\title{
Aproximación al régimen jurídico de la acumulación de mandatos en el ordenamiento jurídico español: una perspectiva desde el ámbito local *
}

\author{
Juan Fernando Durán Alba \\ Profesor de Derecho Constitucional \\ Universidad de Valladolid
}

\begin{abstract}
Sumario: I. INTRODUCCIÓN. II. LAS EXCLUSIONES DE LA ACUMULACIÓN DE MANDATOS EN LOS ORDENAMIENTOS JURÍDICOS EXTRANJEROS: a) La vía de hecho. b) La estricta vía de Derecho. c) La vía mixta, de hecho y de Derecho. III. APROXIMACIÓN AL RÉGIMEN JURÍDICO DE LA ACUMULACIÓN VERTICAL DE MANDATOS EN EL ORDENAMIENTO ESPAÑOL. IV. CONSIDERACIONES ACERCA DE UN HIPOTÉTICO AVANCE EN LA LIMITACIÓN DE LA ACUMULACIÓN VERTICAL DE MANDATOS EN ESPAÑA: ¿HACIA UNA VÍA DE HECHO?
\end{abstract}

\section{INTRODUCCIÓN}

El fenómeno de la «acumulación de mandatos» en España no ha merecido tradicionalmente, ni tampoco desde la literatura jurídico pública contemporánea, una especial atención en contraste con lo que sucede en otros sistemas políticos. Bien es cierto que esta situación de compatibilidad entre cargos representativos, ya sea con el beneplácito expreso de la norma, ya sea debido al silencio de ésta, no parece tener una incidencia excesivamente importante, por lo menos en su dimensión cuantitativa, en lo que a nuestra experiencia política atañe !

\footnotetext{
- El presente texto es una versión corregida y notablemente aumentada de la comunicación que el autor presentó en el Congreso multidisciplinar «Valladolid: hoy y mañana. Presente y futuro de la ciudad", que tuvo lugar en Valladolid entre los días 14 y 18 de octubre de 1996 con ocasión de la celebración del IV Centenario de esta ciudad. Originalmente, el trabajo quedó adscrito a la Ponencia «Democracia municipal y participación ciudadana».

I A la hora de evitar la acumulación de otras actividades con los cargos públicos representativos, se parece más sensible últimamente (por lo menos en las Cortes Generales donde el mandato parlamentario, a través del sistema de incompatibilidades y de la retribución parlamentaria, tiende, en buena medida pienso, a irse profesionalizando) al ámbito privado, debido a los sucesivos escándalos de corrupción que han ido paulatinamente jalonando nuestra escena política.

Con respecto a la presencia de cargos representativos locales en el seno de las Cortes Generales, puede apuntarse que en la presente legislatura, sobre 350 Diputados, únicamente 42 (24 por el PP, 16 por el PSOE, 2 por CiU y 1 por Coalición Canaria) acumulan la condición partamentaria con algún mandato lo-
} 
Varias son las precisiones que, con respecto al objeto y al método, han de realizarse para dejar perfectamente delimitados, desde el principio, los contornos del presente estudio. Así, en cuanto al objeto, deben definirse las dimensiones relativas al significado y a los ámbitos temporales y espaciales en los que debe desenvolverse la exposición. Pero además, deberá justificarse la finalidad de la aproximación —en este caso jurídica - con la que se pretende abordar el elenco de los problemas que suscita la acumulación de mandatos.

En primer lugar, desde un punto de vista semántico, hay que señalar que, en el estricto ámbito de este trabajo, con el término «acumulación de mandatos» se va a hacer referencia a la compatibilidad entre cargos públicos de naturaleza representativa (y por ello legitimados electoralmente) ${ }^{2}$. Se huye, así, de cierta confusión doctrinal que incluiría dentro de esta noción la posible simultaneidad entre cargos no estrictamente representativos, por ejemplo y en el caso francés, entre la condición de Ministro y el cargo de Alcalde ${ }^{3}$.

cal. Los datos se han obtenido de «El pluriempleo de sus señorías» reportaje firmado por E. Jaén y publicado por la revista Tiempo, 28 de octubre de 1996, págs. 14 y ss.

2 Como ya ha sido reiterado por nuestra doctrina, la noción de «cargo público representativo» es un concepto de factura jurisprudencial, construido a partir de diversas resoluciones del Tribunal Constitucional, recaídas en virtud de previos recursos de amparo sustentados, a su vez, en determinadas vulneraciones del artículo 23.2 de nuestra Norma Fundamental. En dicho concepto cabría subsumir ciertos cargos específicos tales como los de Diputado, Senador, parlamentario autonómico o Concejal, éstos sí, específicamente contemplados a lo largo de nuestra Constitución vigente; vid. en este sentido, M. PuLDO QUECEDO, El acceso a los cargos y funciones públicas. Un estudio del artículo 23.2 de la Constitución, Civitas, Madrid, 1992, págs. 253 y ss. Puede encontrarse un intento de construcción doctrinal de la noción de cargo público representativo por F. J. GaRcfa RoCA, «La difícil noción de cargo público representativo y su función delimitadora de uno de los derechos fundamentales del artículo 23.2 de la Constitución», Revista de las Cortes Generales, núm. 34, primer cuatrimestre 1995, págs. 51 y ss.

En el sentido, pues, dado al mandato seguimos las tesis de: A. y Fr. Demichel, Droit électoral, Dalloz, París, 1973, págs. 231 y ss.; o también M. ReYdellet, «Le cumul des mandats», Revue de Droit Public et de la Science Politique en France et à l'Étranger, mayo-junio 1979, pág. 697.

3 Incluyen, entre otros, este tipo de compatibilidad dentro de los supuestos de acumulación de mandatos: J. BeCQUART-LECLERC, «Cumul des mandats» (voz) en: Dictionnaire constitutionnel (dirs. Y. Mény y O. Duhamel), Presses Universitaires de France, París, 1992, pág. 259; también en este mismo sentido, Y. MÉNY, «Las restricciones a la acumulación de mandatos: ¿reforma simbólica o cambio en profundidad?» (traducción de E. Lorenzo Serra), Revista del Centro de Estudios Constitucionales, núm. 6, mayo-agosto 1990, pág. 177.

Efectivamente, desde el momento en que, a tenor de lo dispuesto en el artículo 23 de la Constitución francesa, los Ministros no pueden acumular su condición ejecutiva con el mandato parlamentario, difícilmente puede otorgarse al cargo ministerial una naturaleza representativa. Sin embargo, el Alcalde reúne, a la vez que una indudable condición ejecutiva, una naturaleza representativa pues, ya sea designado por y de entre los Concejales ya sea elegido directamente por el electorado - en este último caso sin duda alguna-, participa mediante su voto en la formación de la voluntad del órgano representativo local.

Así, entre nuestros autores, F. J. GARCía ROCA sostiene que, pese a una inicial doctrina del Tribunal Constitucional que ha parecido diferenciar entre los Concejales y Alcaldes a los efectos de otorgarles a estos últimos una naturaleza representativa, aunque la elección del Alcalde no sea directa por parte de los ciudadanos sino que traiga su causa de una designación por parte de los Concejales, ello no le priva de 
APROXIMACIÓN AL RÉGIMEN JURIDICO DE LA ACUMULACIÓN ...

En segundo lugar, y con respecto al ámbito temporal de la acumulación, ésta va a entenderse como contemporánea, o sea, cuando los mandatos se desempeñan simultáneamente y no de forma sucesiva ${ }^{4}$. Así pues, quedan fuera de nuestro análisis eventuales consideraciones sobre la oportunidad o no de limitar el desempeño, a lo largo del tiempo, del mandato representativo no haciendo posible la reelección del cargo público.

En tercer lugar, conviene determinar el ámbito espacial en el que va a desenvolverse el presente estudio. En concreto, no vamos a detenernos en la denominada «acumulación horizontal» de mandatos, o lo que es lo mismo, entre aquellos desempeñados en el mismo nivel territorial. Esta posibilidad aparece rotundamente excluida en los sistemas de Parlamentos bicamerales quedando proscrita la posibilidad de ostentar simultáneamente la condición de representante en la Cámara baja y en la Cámara alta. La prohibición puede tener mero rango legal ${ }^{5}$ o bien estimarse que debe constar expresamente ex costitutione ${ }^{6}$. Lo cierto es que esta habitual interdicción no ha suscitado controversias doctrinales, por lo menos desde el punto de vista de su oportunidad, apareciendo como «un corolario lógico y una exigencia de la propia estructura parla-

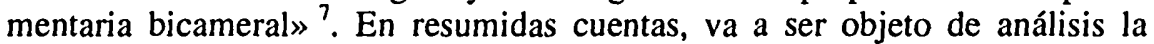

la citada naturaleza (cfr. op. cit., pág. 74). Debe recordarse que la referida jurisprudencia se dictó para resolver recursos de amparo (así, STC 5/1983 «Ayuntamiento de Andújan» y ATC 6/1984 «Ayuntamiento de Rincón de la Victoria) que hacían referencia a problemas muy concretos.

4 Sobre la «acumulación temporal» como modalidad de este fenómeno vid. J. BECQUART-LECLERC, op. cit., pág. 259.

5 En el Reino Unido, la House of Commons Disqualifications Act de 1975, impide a los Pares formar parte de la Cámara de los Comunes; contrario sensu, para formar parte de la Cámara de los Lores, debe ostentarse la condición de Par, con lo cual, un Commoner designado Par por la Corona debería renunciar a su mandato en la Cámara baja si quisiera acceder a la Cámara alta. En Francia el Code Électoral, en su artículo 137, párrafo 1. , prohíbe la simultaneidad de mandatos entre la Asamblea Nacional y el Senado.

6 Es nuestro caso, donde el artículo 67.1 de la Constitución prescribe que: «Nadie podrá ser miembro de las dos Cámaras simultáneamente...». La opción por prohibir in radice, desde la misma Constitución, cualquier posibilidad de simultanear el mandato parlamentario entre ambas Cámaras se encuentra también en: artículo 59 de la Constitución austriaca, artículo 49 de la Constitución belga, artículo 15, apartado 14, de la Constitución irlandesa, artículo 65, párrafo 2. ${ }^{\circ}$, de la Constitución italiana, artículo 57.1 de la Constitución de los Países Bajos, en fin, artículo 77 de la Constitución suiza.

7 Con estos términos, P. DE VEGa GaRClA, «Artículo 67. La prohibición de acumulación de mandatos y del mandato imperativo y la obligación de convocatoria reglamentaria de las Cámaras», y, en este mismo sentido, A. FERNANDEZ-MIRANDA Y CAMPOAMOR, "Artículo 70. Causas de inelegibilidad e incompatibilidad y control judicial de las actas electorales", ambos trabajos se encuentran recogidos en: Comentarios a las Leyes Políticas (dir. O. Alzaga Villaamil), tomo VI, EDERSA, Madrid, 1989, cfr., en especial, págs. 81 y 259 , respectivamente.

A pesar de que parezca tan obvia la prohibición de acumular horizontalmente dos mandatos puede señalarse, como anécdota, que en Francia hubo de establecerse legalmente en 1927 ante la práctica viciada, durante la III República, de algunos Diputados posteriormente elegidos Senadores, que tardaban meses en 
«acumulación vertical» o compatibilidad de los mandatos representativos en distintos niveles territoriales.

Es cierto que, desde un punto de vista político, el fenómeno a que nos referimos ofrece dimensiones marcadamente contrapuestas. Así, entre las ventajas que tradicionalmente aparecen ligadas a la posibilidad de acumular los mandatos representativos puede sostenerse que: sirve como un medio de influencia del parlamentario en el desarrollo económico local ${ }^{8}$, o bien que favorece las posibilidades de intercomunicación entre los diversos escalones territoriales de gobierno - central, regional y local $-{ }^{9}$, por no citar las que aporta, personalmente, al propio acumulante ${ }^{10}$.

Mas no sería honesto ocultar que la acumulación ha sido también ferozmente combatida: en este sentido, se arguye, puede producirse una feudalización de la vida local en tanto que el mandatario municipal o regional se vincula a la consecución de intereses distintos de aquéllos para los que fue elegido en las circunscripciones territorialmente inferiores "; o bien la habitual sospecha de falta de eficacia en el desempeño de varias funciones a la vez ${ }^{12}$; por fin, sin pretender agotar el elenco de fatalidades, debe citarse el recurso al tan manido absentismo parlamentario por estar los mandatarios nacionales atendiendo a funciones locales o a la inversa ${ }^{13}$.

Pero el enfoque de esta comunicación pretende ser eminentemente jurídico $y$, por ello, no se va a construir un elenco de justificaciones teóricas que pudieran avalar la opción, siempre políticamente legítima para el legislador, de incli-

dimitir de su mandato en la Asamblea para simultanear durante un tiempo ambas funciones, vid. $\mathrm{M}$. CEOARA, «Les incompatibilités parlementaires en France et à l'étranger», Notes et Études Documentaires, La Documentation Française, núms. 4102-4103, 10 de julio de 1974, pág. 14.

8 Vid. A. Chandernagor, Un Parlement pour qoui faire?, Gallimard, St. Armand, 1967, pág. 153.

9 En este sentido J. BeCQUART-LeCLERC, op. cit., pág. 260.

10 Entre éstas: servir de trampolín político, procurar facilidades logísticas y financieras para las sucesivas campañas electorales y, por supuesto, garantizar la continuidad política en el caso de derrota electoral en alguno de los mandatos ( $c f r$. idem).

11 En esta línea, p. ej., J.-M. BelorgeY, Le Parlement à refaire, Gallimard, Mesnil-sur-L'Estrée, 1991, pág. 100.

12 Entre nosotros: A. Fernández-Miranda y Campoamor, op. cit., págs. 275 y ss. También E. Reco DER DE CASSO, «Comentario al artículo 67», en: Comentarios a la Constitución (dir. F. Garrido Falla), Civitas, Madrid, 1985 (2." edic.), pág. 1.032.

13 J. Boudant, «La crise identitaire du Parlement français», Revue de Droit Public et de la Science Politique en France et à l'Étranger, núm. 5/1992, septiembre-octubre, págs. 1.364 y ss. En este sentido, al describir la situación del Parlamento italiano, L. LIBERTINI (Quale Parlamento? Osservazione e proposte sull'istituto parlamentare, Einaudi, Turín, 1977) ha sostenido que, en contra de lo comúnmente creido, el ab- 
APROXIMACIÓN AL RÉGIMEN JURTDICO DE LA ACUMULACIÓN ...

narse de un lado o de otro (es decir, permitiendo o restringiendo), a la hora de elaborar el régimen jurídico de la materia que ahora se expone. En su caso, lo que nos corresponde es tratar de determinar la vía jurídicamente adecuada para realizar una eventual restricción del fenómeno que aquí se estudia.

En fin, parece también oportuno tratar de explicar las soluciones que en otros ordenamientos jurídicos se han arbitrado de cara a evitar la acumulación. Particularmente interesa, dentro de la tendencia moderna a aislar el mandato representativo de otras actividades públicas o privadas, analizar los medios empleados para excluir de los órganos parlamentarios a quienes ya ostentan algún otro cargo representativo ${ }^{14}$.

\section{LAS EXCLUSIONES DE LA ACUMULACIÓN DE MANDATOS EN LOS ORDENAMIENTOS JURÍDICOS EXTRANJEROS}

\section{a) La vía de hecho}

Con esta expresión se alude al hecho de que el ordenamiento jurídico guarde silencio ante la acumulación de mandatos y que, no obstante, ésta sea inexistente debido, principalmente, a la práctica política.

Dentro de esta primera posibilidad se encuentra el Reino Unido. En efecto, ni la House of Commons Disqualifications Act de 1975, desde el punto de vista del Parlamento nacional, ni la Local Government Act de 1972 (reformada, sucesivamente, en 1985 y 1992), desde el punto de vista municipal, descalifican para formar parte de cualquiera de ambas instancias representativas a quienes sean representantes por la otra ${ }^{15}$. Sin embargo, por mor de la práctica el mandato único se ha impuesto sin que las normas jurídicas hayan previsto ningún límite para la acumulación ${ }^{16}$. Principalmente, al legislador británico le ha inte-

sentismo de las Cámaras no está provocado tanto por la dedicación de los representantes a sus actividades privadas, sino antes bien, a tareas eminentemente políticas; entre ellas, recogía el citado autor, la de ocuparse en los distintos organismos oficiales de los asuntos de sus respectivas circunscripciones (pág. 12).

14 Al margen del criterio sistemático empleado para examinar el ordenamiento jurídico extranjero que va a exponerse a continuación, pueden verse algunos ejemplos de incompatibilidades entre mandatos electivos, de forma comparada en: Les Parlements dans le Monde. Recueil de données comparatives (preparado por V. Herman y F. Mendel), editado por la Unión Interparlamentaria y Presses Universitaires de France, París, 1977, pág. 162.

is Vid. O. H. Phillips y P. Jackson, O. Hood Phillips' Constitutional and Administrative Law, Sweet \& Maxwell, Londres, 1987 (7." edic.), págs. 179 y ss. para el Parlamento y 589 y ss. para las elecciones locales. También, Ch. Cross, y S. Balley, Cross on Local Govemment Law, Sweet \& Maxwell, Londres, 1986, págs. 275 y ss.

16 Vid. J.-CL. MASCLET, «Un remède homéopathique? Les lois sur la limitation des cumul des mandats et fonctions électifs", Actualité Juridique-Droit Administratif, núm. 4, 20 de abril de 1986, pág. 215. 
resado prohibir de forma expresa, en mayor o menor medida, la presencia en las instancias representativas (ya sean nacionales o locales) de funcionarios o servidores públicos que pudieran quedar afectos a los intereses de quien les ha empleado en demérito de las labores propias del cargo representativo ${ }^{17}$.

Dicha preocupación, si bien históricamente halla su causa en los esfuerzos del Parlamento por verse libre de las injerencias de la Corona sobre la libre formación de su voluntad (intromisión que encuentra su expresión más álgida, como resulta conocido, a través de la promoción por parte del Rey de los representantes a cargos ejecutivos, genéricamente a los Office of profit under the (rown), tiene hoy en día otras explicaciones. La ausencia de empleados públicos en las instancias representativas - sean parlamentarias o municipales- supone un elemento más a favor de la consagración de la Administración pública - nacional o local- como una burocracia permanente, profesionalizada y, sobre todo, políticamente neutral ${ }^{18}$.

Lo reflejado sobre el recurso a la praxis política vale, asimismo, de cara a las eventuales acumulaciones entre los mandatos nacionales y los europeos. En efecto, frente al silencio de la norma que, a diferencia de lo que sucede en otros países europeos (por ejemplo en Francia y en España), no declara incompatibles ambas condiciones representativas, debe estarse al criterio de los partidos políticos sobre esta cuestión. En este sentido, el Partido Laborista ha desaconsejado la acumulación de mandatos, mientras que el Partido Conservador la encuentra perfectamente admisible ${ }^{19}$.

\section{b) La estricta vía de Derecho}

Se utiliza esta expresión en el sentido de que el legislador, a través de normas jurídicas concretas, haya pretendido limitar las específicas situaciones de compatibilidad que se ahora se estudian ${ }^{20}$.

\footnotetext{
17 Pueden verse de manera comparada el sistema de exclusiones (disqualifications) en el ámbito parlamentario y municipal, referentes al Reino Unido, en H. F. RawLINGS, Law and Electoral Process, Sweet \& Maxwell, Londres, 1988, págs. 111 y ss.

18 Vid., con relación al sistema británico, L. PAREjo ALFonso, Derecho básico de la Administración local, Ariel, Barcelona, 1988, pág. 267.

19 No obstante, la práctica, una vez más, ha sido la de no acumular ambos cargos. Así, se señala el hecho de que en 1995 únicamente existieran tres europarlamentarios británicos que, a la vez, ejercieran el correspondiente mandato nacional, vid. J. BEAUTE, «Le Règlement intérieur de la Chambre des communes britaniques d'hier à aujourd'hui», Revue de Droit Public en France et à l'Étranger, núm. 6/1996, noviembre-diciembre, pág. 1.570 .
}

20 Además del sistema francés que va a ser objeto de consideración seguidamente, puede apuntarse que, en Bélgica, desde 1921, a través de la Ley Orgánica de Elecciones Provinciales, se ha declarado incompatible el mandato parlamentario con la condición de Consejero provincial ( $c f r$. el art. 25.1 de la citada norma); el dato se ha extraído de M. CEOARA, op. cit., pág. 40. Más recientemente ha sido ensayada 
Desde la técnica jurídica, la restricción de la acumulación de mandatos se puede abordar a través de dos instrumentos distintos: la inelegibilidad y la incompatibilidad. Sabido es que la primera impide al incurso en una causa de inelegibilidad concurrir como candidato en las elecciones, salvo que enerve la prohibición a través de la previa renuncia al cargo que ostenta. Sin embargo, la incompatibilidad, sin impedir la concurrencia electoral, obliga al candidato electo a optar entre la función declarada incompatible y el mandato representativo ${ }^{2 !}$. En las páginas siguientes podrá examinarse en qué casos se ha empleado una u otra técnica ${ }^{22}$.

En cuanto a la técnica normativa. El encaje de la prohibición puede residenciarse en la correspondiente Constitución: es el caso de la incompatibilidad derivada de la pertenencia a la vez a la Cámara alta y a la Cámara baja ${ }^{23}$, pero también, en algún caso, determinadas previsiones que afecten a las Asambleas representativas regionales o locales ${ }^{24}$. Lo normal, no obstante, es dejar en manos del legislador ordinario la configuración del régimen jurídico que afecta a este supuesto.

El caso francés resulta tópico en lo que respecta a la acumulación de mandatos. Tanto la Constitución vigente como las iniciales normas electorales del

la prohibición de la presentación de candidaturas simultáneas a la Cámara, Senado y Consejo Provincial en el caso de que las elecciones resulten coincidentes; vid., en este sentido, la Proposición del Diputado V. Féaux (Chambre des Représentants, 483/1-91/92, sesión extraordinaria, 27 de mayo de 1992); en idénticos términos el Diputado P. Tant (Chambre des Représentants, 562/1-91/92, sesión extraordinaria, 1 de julio de 1992). Posteriormente, se ha intentado la prohibición general de acumular todo tipo de mandatos; así la Proposición presentada por los Diputados G. Verhofstadt y P. Dervael (Chambre des Représentants, 998/1-92/93, sesión ordinaria, 7 de mayo de 1993). Ya desde el Derecho vigente, la Ley de 30 de diciembre de 1993, ha incluido en la vieja legislación de incompatibilidades de 1931 a los «Senadores de comunidad»; así, se ha declarado la incompatibilidad de este específico cargo parlamentario con cualquier cargo electivo local.

21 Vid. un intento riguroso de delimitación de ambos institutos jurídicos por A. FERNANDEZ-MIRANDA, op. cit., págs. 234 y ss., y más específicamente págs. 238 y 239.

22 No han pasado desapercibidos los defectos de un sistema que, sustentado únicamente en un conjunto de causas de inelegibilidad e incompatibilidad, pretenda alejar de la esfera representativa determinados intereses. Defectos que van desde limitar las exclusiones a los empleados públicos, quedando impunes determinados intereses privados que pudieran colisionar con los públicos, a las deficiencias derivadas de un sistema de control sobre las inelegibilidades e incompatibilidades -en mayor medida sobre éstas- escasamente riguroso. Véase sobre este particular $y$, precisamente en el ámbito local, $F$. PINTo, Gli amministratori locali nella democrazia contemporanea. Riflessioni critiche in tema di ineleggibilità ed incompatibilità, Giuffrè, Milán, 1984, págs. 133 y ss.

23 Véase supra nuestra nota a pie de página número 6.

24 El artículo 67.1 de nuestra Constitución impide «acumular el acta de una Asamblea de Comunidad Autónoma con la de Diputado al Congreso». También el artículo 122, párrafo $2^{\circ}$, de la Constitución italiana, que hace lo propio con los mandatos regionales y nacionales. Un caso curioso es el de la Constitución griega que, en su artículo 56.1, declara inelegibles a los Alcaldes y Presidentes de Ayuntamiento (no así a los Concejales). 
actual período republicano guardaban silencio ante lo que, tradicionalmente, ha constituido un fenómeno peculiar de este sistema ${ }^{25}$. Sin embargo, esta situación llegó a posibilitar que los mandatos representativos se hubieran acumulado en muy pocas manos. En numerosas ocasiones, tanto desde la doctrina científica ${ }^{26}$ como desde la política ${ }^{27}$, se había solicitado una limitación de lo que se consideraba ya un mal endémico del sistema político galo. En este contexto, el legislador vecino, a través de sendas normas, ha pretendido limitar a partir de 1985 la acumulación de mandatos.

La vía seleccionada ha sido la de la incompatibilidad. Por lo tanto, no se obliga a dimitir de los cargos acumulados para concurrir como candidato en el proceso electoral, sino que, una vez electo, debe optarse por uno de los mandatos adquiridos. Concretamente, el artículo 141 del Código Electoral declara incompatible con el mandato de Diputado el ejercicio de más de uno de estos cargos: representante en el Parlamento Europeo, Consejero regional, Consejero general, Alcalde de una ciudad de 20.000 o más habitantes que no sea $\mathrm{Pa}$ rís, Teniente de Alcalde de una ciudad de 10.000 o más habitantes que no sea París ${ }^{28}$.

En lo que respecta a su virtualidad la nueva legislación no ha estado exenta de críticas. En este sentido, las objeciones son de variada índole: se ha llegado a afirmar que todavía en 1988, el $96 \%$ de los Diputados ostentaban, al menos, un mandato local ${ }^{29}$; también se afirma que se ha utilizado la técnica de poner candidatos afines (incluso familiares) de cara a ocupar los cargos que debían abandonarse ${ }^{30}$. Por otra parte, desde los intereses del Parlamento, hay autores que no están de acuerdo con que la acumulación redunde en la eficacia del tra-

\footnotetext{
25 Así, p. ej., entre otros M. ReYdellet, «Le cumul des mandats», op. cit., págs. 693 y ss. Para el modo de configurar la acumulación de mandatos como un elemento indispensable, aún mas, indefectiblemente ligado al cursus honorum político, vid. R. CAYROL; J.-L. PARODI y C. YSMAL, Le député français (publicado dentro de los Cahiers de la Fondation Nationale des Sciences Politiques, núm. 23), Libr. A. Colin, París, 1973, págs. 128 y ss.
}

26 Véanse por todos, J.-P. COT y P. GABORr, Citoyens et candidats. La pratique des élections, Robert Laffont Eds., París, 1977, págs. 195 y ss.

27 J. Julliard, Contre la politique professionnelle, Seuil, París, 1977, pág. 143.

28 En virtud del artículo 297 del mismo cuerpo legal, las causas de incompatibilidad para los Diputados son de aplicación a los Senadores. Las referencias normativo electorales del Derecho francés se han obtenido del: Code Électoral (edic. preparada por B. Maligner), Dalloz, París, 1995.

29 Cfr. los datos en Y. MÉNY, «Le cumul des mandats ou l'imposible séparation des pouvoirs?», Povoirs, núm. 64, 1993, pág. 131.

30

lbid., pág. 132. 
bajo parlamentario pues se suele dar prioridad a este mandato —el nacionalsobre los demás ${ }^{31}$.

Lejos de encontrarnos ante un proceso cerrado, debe indicarse que existen varias propuestas parlamentarias, por el momento sólo Derecho proyectado, destinadas a endurecer el sistema de incompatibilidades introducido por la legislación anti-cumul de $1985^{32}$, o bien, desde un punto de vista técnico, a mejorar el régimen aplicativo para evitar el fraude de ley. Parece práctica habitual el que, como la legislación de 1985 operó a través de la incompatibilidad, los candidatos se presentan a las elecciones aprovechando su tirón electoral derivado de sus cargos locales o regionales, o la inversa, para después optar una vez conseguido el mandato por el cargo anterior y que pase a ocupar el conseguido ulteriormente el candidato siguiente de la lista ${ }^{33}$.

\section{c) La vía mixta, de hecho y de Derecho}

El caso italiano ha sido seleccionado porque si bien aparentemente, a través de la ley, se ha limitado la posibilidad de acumular mandatos, en algún caso se ha acudido a la práctica parlamentaria para, mediante una interpretación forzada de la norma, llegar a un resultado no previsto por ésta (de ahí, pues, el recurso a la expresión «vía de hecho»).

Con respecto, en primer lugar, a la relación entre mandatos nacionales y regionales, ya, desde la propia Constitución, se ha previsto la imposibilidad de desempeñar de forma conjunta el mandato parlamentario con el cargo de Consejero Regional (artículo 122, párrafo $\left.2 .^{\circ}\right)^{34}$. Pero el legislador nacional entendió la

31 M. Ameller, L'Assemblée Nationale, Presses Universitaires de France, París, 1994, pág. 33.

32 Así, p. ej., la Proposición de ley presentada por el Diputado M. Noir (Assemblée Nationale, núm. 2912, IX Legislatura, 17 de julio de 1991) en el sentido de restringir la acumulación del mandato parlamentario con un solo cargo representativo. En el año 1994 se presenta toda una batería de proposiciones en este sentido: así, la del Diputado J.-L. Masson (Assemblée Nationale, núm. 1623, X Legislatura, 12 de octubre de 1994) destinada a reforzar las incompatibilidades entre mandatos, así como entre el cargo parlamentario y las actividades profesionales; exclusivamente en referencia a la acumulación de mandatos destacan la de los Diputados P. Mazeaud (Assemblée Nationale, núm. 1710, X Legislatura, 22 de octubre de 1994) y M. Malvin et al. (Assemblée Nationale, núm. 1736, X Legislatura, 29 de octubre de 1994). Por su parte, en el Senado, pueden hacerse constar dos proposiciones del Senador J. Rocca Serra destinadas a impedir la acumulación pero únicamente entre cargos representativos locales (Sénat, núm. 91, 28 de noviembre de 1994) y, el caso de los mandatos nacionales, a restringir la acumulación con un solo cargo local (Sénat, núm. 95, 28 de noviembre de 1994).

33 Para evitar esta práctica, vid. la Propuesta de Ley de reforma del Code Électoral presentada por el Diputado J.-L. Masson (Assemblée National, núm. 2855, IX Legislatura, 30 de junio de 1992) según la cual el parlamentario acumulante perdería el mandato anterior en beneficio del adquirido en último término.

34 Las referencias al ordenamiento jurídico italiano se han contrastado en: Leggi fondamentale del diri- 
disposición constitucional, en el juego de las relaciones entre ambos entes territoriales, de distinta forma: para los Diputados y Senadores, la norma reguladora de las elecciones a los Consejos Regionales, en aplicación del precepto constitucional citado prevé la incompatibilidad de cargos ${ }^{35}$; sin embargo, con relación a los Consejeros regionales, el artículo 7.1 del Texto Único para las Elecciones a la Cámara de Diputados, en su letra a), preveía una causa de inelegibilidad si aquéllos pretendían ser candidatos al Parlamento nacional ${ }^{36}$.

Por su parte, en segundo lugar, la relación entre mandatos regionales y locales se construye, para algunos cargos, desde la incompatibilidad. En virtud del artículo 4, párrafo $1 .^{\circ}$, de la ya citada norma sobre elecciones a los Consejos regionales, los mandatos regionales no son acumulables con el cargo de $\mathrm{Al}-$ calde.

Resta examinar, en tercer lugar, las relaciones entre los mandatos nacionales y locales. El artículo 7 del aludido Texto Único para las elecciones a la Cámara de Diputados, en sus letras b) y c), declara inelegibles a los Presidentes de las Juntas Provinciales y a los Alcaldes (Sindaci) de poblaciones con más de 20.000 habitantes.

¿Cómo, entonces, a tenor de lo expuesto puede hablarse de exclusión de hecho existiendo tan detallada previsión legislativa? El problema ha derivado de un incorrecto entendimiento de los fines perseguidos por dos institutos jurídicos distintos: la inelegibilidad y la incompatibilidad. Como se ha visto, la ley electoral impide a los Alcaldes presentarse a los comicios nacionales, mas nada prevén los textos legales para el supuesto del Diputado, válidamente electo,

tto pubblico e costituzionale (AA.VV.), Giuffrè, Milán, 1994 (18." edic.) y, asimismo, en el Codice elettorale, editado por la Presidencia del Consejo de Ministros, Roma, 1994.

35 Cfr. el artículo 4, párrafo 1. ${ }^{\circ}$, de la Ley núm. 154, de 23 de abril de 1981, que reforma la Ley de 1968, relativa a la elección de los Consejeros regionales, en materia de inelegibilidades e incompatibilidades. Nótese que, por obra del citado artículo 122 de la Constitución italiana, la competencia para legislar sobre las elecciones regionales recae sobre el Parlamento nacional y no, a diferencia de nuestro sistema, en los órganos legislativos regionales.

36 Esta diferencia de tratamiento, por parte del legislador estatal, ha sido enjuiciada por la Corte Constitucional que, en su sentencia núm. 344, de 28 julio de 1993, declaró no conforme con la Constitución la inelegibilidad de los Consejeros regionales; vid. M. VoLPI, «L'ineleggibilità al Parlamento dei consiglieri regionali tra declaratoria di inconstituzionalità e necessità di una nuova disciplina legislativa” en Giurisprudenza Costituzionale, núm. 4/año XXXVIII, julio-agosto 1993, págs. 2.695 y ss. Abiertamente contrario a la anulada inelegibilidad se había mostrado L. PRETı (Diritto elettorale politico, Giuffrè, Milán, 1957); para este autor, el fundamento de que quienes ostenten tales cargos pueden influir en el proceso electoral, no se sostiene en la medida en que otros cargos políticos (Ministros o Subsecretarios) también pueden hacerlo y no han resultado declarados inelegibles por la ley (pág. 179). 
APROXIMACIÓN AL REGIMEN JURÍDICO DE LA ACUMULACIÓN ...

que adquiere el cargo municipal a posteriori ${ }^{37}$. Nos hallamos, técnicamente, ante lo que se denomina como una «inelegibilidad sobrevenida».

Pues bien, la práctica parlamentaria cuando ha surgido alguna situación de las comentadas, concretamente cuando algún Diputado ha sido posteriormente elegido Alcalde, ha sido la de estimar que lo que constituía una inelegibilidad sobrevenida convertíase en una causa de incompatibilidad y por ello se obligaba al parlamentario a optar entre ambos cargos ${ }^{38}$. Ello quiere decir, en consecuencia, que se ha utilizado indebidamente una técnica (la inelegibilidad) diseñada para desplegar sus efectos durante el proceso electoral para, a través de su conversión en un instituto jurídico parlamentario pensado para proteger la independencia del cargo representativo (la incompatibilidad), privar al representante de uno de sus cargos. Esta conversión parlamentaria, es cierto, sigue una tendencia histórica en Italia consistente en declarar incompatibles a los Alcaldes y que parecía haberse quebrado con la nueva legislación ${ }^{39}$. Pero interesa apuntar que el medio para estimar la incompatibilidad, al no contar con un previo encaje normativo, provoca, al menos, una vulneración del principio de seguridad jurídica por cuanto coloca al parlamentario elegido Alcalde al albur de la decisión de la correspondiente Cámara que pudiera, discrecionalmente, seguir uno u otro criterio desde la inexistencia legal de la incompatibilidad.

Esta situación es particularmente grave si se tiene en cuenta que, en Italia, el representante no tiene ningún mecanismo extraparlamentario de garantía frente a una declaración de la Cámara lesiva de sus intereses ${ }^{40}$. No se discute,

37 Las normas sobre incompatibilidades parlamentarias guardan silencio sobre los cargos municipales.

Puede verse la consolidación de tal práctica en M. MIDIRI, «Articolo 65», Commentario della Costituzione (a cura di G. Branca): Le Camere, tomo II, Zanichelli y Ed. del Foro, Bolonia y Roma, 1986, págs. 91 y ss. La declaración de incompatibilidad se produce en virtud del correspondiente pronunciamiento de la Giunta delle elezioni que es el órgano parlamentario competente a estos efectos. Curiosamente, mientras en el Senado en el caso de declaración de incompatibilidad, el Senador dispone de una suerte de juicio contradictorio (giudizio di contestazioni) ante la Asamblea en el que tras un eventual debate se procedería a la votación, tal posibilidad no existe en la Cámara de Diputados (vid. M. L. MAzzoN! Honoratı, Lezzioni di Diritto Parlamentare, Giappichelli, Turín, 1991, págs. 129-130).

Véase la evolución normativo histórica de esta incompatibilidad en Italia leyendo: G. DE GENNARO, «Incompatibilità tra Deputato al Parlamento e Sindaco", L'amministrazione italiana, año VII, 1952, en especial págs. 825 y ss.

39 Así, L. MASSINI, «Ineleggibilità ed incompatibilità nella legge elettorale politica», L'Amministrazione italiana, año XII, 1967, pág. 1.139.

40 Los actos parlamentarios no legislativos sin transcendencia externa (interna corporis acta), de acuerdo con el principio de división de poderes no son fiscalizables por la jurisdicción ordinaria (vid. $\mathrm{V}$. DI Cıolo, «Incompatibilità parlamentare e conflitto fra poteri», Giurisprudenza Costituzionale, 1966. Tomo I, pág. 669). Además, no existe un recurso de amparo ante la Corte Costituzionale análogo al operado, en nuestro ordenamiento, en virtud del artículo 42 de la Ley Orgánica del Tribunal Constitucional frente a los actos parlamentarios lesivos de los derechos fundamentales. En fin, el parlamentario 
para terminar, la oportunidad de la incompatibilidad sino el mecanismo jurídico para introducirla; en este sentido estimamos como más correcto su creación a través de su inserción en la norma jurídica sobre incompatibilidades ${ }^{41}$

\section{APROXIMACIÓN AL RÉGIMEN JURÍDICO DE LA ACUMULACIÓN VERTICAL DE MANDATOS EN EL ORDENAMIENTO ESPAÑOL}

El orden elegido para realizar el examen normativo va a ser de carácter descendente, esto es, ha de comenzarse por analizar las normas referentes a las incompatibilidades de los mandatos nacionales para terminar con las referidas al ámbito local.

Procede, en primer lugar, determinar con qué otros mandatos representativos pueden o no acumularse los cargos de Diputado o Senador. Nuestra vigente Constitución, únicamente se refiere a la acumulación vertical de mandatos en el artículo 67.1, cuando impide acumular los cargos de Diputado con la condición de parlamentario autonómico (no lo veda, pues, en el caso de los Senadores). Apenas suscita dudas el que, puesto el anterior precepto en conexión con el 70.1 del mismo cuerpo normativo, nada impide ex costitutione que el legislador de desarrollo, bien a través de la inelegibilidad, bien a través de la incompatibilidad (incluso mediante ambas técnicas), amplíe la prohibición de los supuestos jurídicos referentes al desempeño simultáneo de mandatos representativos. Y así ha sido, siempre desde la perspectiva de la acumulación vertical, el artículo 154.2 LOREG transforma la incompatibilidad con los mandatos parlamentarios autonómicos en causa de inelegibilidad pero únicamente en el caso de los Presidentes de Comunidad Autónoma y además con respecto del Congreso de los Diputados pues nada refiere para el Senado ${ }^{42}$. Por lo demás,

italiano, individualmente considerado, queda excluido de la vía del «conflicto de atribuciones» sólo planteable entre poderes del Estado (vid., entre nosotros, F. J. GARCía RocA, El conflicto entre órganos constitucionales, Tecnos, Madrid, 1987, en especial pág. 31 para el ámbito parlamentario y pág. 32 para entidades territoriales menores; también A. J. MoNTORo GómEZ, El conflicto entre órganos constitucionales, Centro de Estudios Constitucionales, Madrid, 1993, pág. 166).

41 Seguimos así a V. DI CIOLO y L. CiAurRo, Il diritto parlamentare nella teoria e nella pratica, Giuffrè, Milán, 1994 (3. edic.), pág. 173. Concretamente, la incompatibilidad debería, en buena técnica, figurar en la Ley núm. 60, de 15 de febrero de 1953, sobre incompatibilidades parlamentarias. Cabe apuntar, en la línea mantenida en este trabajo, la propuesta del Diputado Polizio (Atti Parlamentari, Camera dei Deputati, núm. 2025, XI Legislatura, Disegni di Legge e Relazioni Documenti, 15 de diciembre de 1992) en el sentido de arbitrar la incompatibilidad del mandato parlamentario con los cargos de: Consejero regional, Alcalde metropolitano, Presidente de provincia que tenga más 250.000 habitantes y Alcalde de población con más de 100.000 habitantes.

42 Se incluye a los Presidentes de las Comunidades Autónomas entre los mandatos regionales porque, 
vuelve a reiterarse la incompatibilidad del artículo $67.1 \mathrm{CE}$-así la horizontal como la vertical- en el artículo 155.3 LOREG. Por último, la norma electoral introduce, en su artículo 211.2 letras c) y d), la incompatibilidad del mandato parlamentario europeo con los cargos de Diputado, Senador y miembros de las Asambleas regionales ${ }^{43}$; aunque, no toma en cuenta a los mandatos locales çon lo que debe estimarse la compatibilidad.

El segundo nivel territorial lo constituyen las Comunidades Autónomas. En éstas, las inelegibilidades e incompatibilidades se recogen por el legislador regional en virtud de una previa remisión estatutaria ${ }^{44}$. Y en este aspecto cobra especial relevancia, precisamente, el Estatuto de la Comunidad castellano leonesa por cuanto, además de remitirse al legislador electoral en estas materias (artículo 11.4), dispone que:

«En cualquier caso, la condición de procurador será compatible con la de Diputado provincial y con la de Concejal» ${ }^{45}$.

en puridad y a diferencia de lo que sucede con el Presidente del Gobierno, siempre debe ser de extracción parlamentaria al estar elegidos por y de entre los miembros de la Asamblea legislativa regional correspondiente.

Radicalmente en contra de que no se prevea para el Senado, pues aun siendo la Cámara de representación territorial, el Presidente de la Comunidad Autónoma es la cabeza del órgano ejecutivo regional y existe, por lo tanto, una más que apreciable colisión de intereses, vid. A. FernándeZ-Miranda Y CAMPOAMOR, op. cit., págs. 275 y ss.

43 Curiosa incompatibilidad cuando acto seguido, en el apartado $3 .^{\circ}$ del mismo precepto, se hace operar la pérdida del cargo incompatible de forma automática. Esto es, el Diputado o Senador electo al Parlamento Europeo adquiere la condición de europarlamentario sin poder optar entre los cargos representativos que posee; facultad de optar, por cierto, de antiguo ínsita al régimen jurídico de las incompatibilidades. Obligación que es explicable - pero discutible-, en último término, para evitar que, desde la existencia de una circunscripción nacional única en el proceso electoral al Parlamento Europeo, determinados Diputados o Senadores aprovechen su carisma o tirón electoral para conseguir algún euroescaño y, acto seguido, renunciar en favor de los siguientes candidatos de la lista.

Esta norma fue recurrida ante el tribunal Constitucional por el Gobierno Vasco al entender que había una contradicción entre el Acta comunitaria de 1976 relativa a las elecciones al Parlamento Europeo (que prevé la acumulación de mandatos nacionales y comunitarios en su art. 5) y la norma electoral española introductoria de la incompatibilidad, en contraste con los artículos 93 y 96 de nuestra Norma fundamental. El Tribunal, en su Sentencia 28/1991, de 14 de febrero, estimó que no existía contradicción con nuestra Constitución y las antinomias entre las leyes estatales y las normas comunitarias no son de su conocimiento (fundamento jurídico $5^{\circ}$ ). En contra de esta incompatibilidad, J. C. DA SILVA OCHOA, «La legislación española sobre elecciones al Parlamento Europeo: La cuestión del doble mandato", Revista de Instituciones Europeas, núm. 2/volumen 15, 1985, pág. 497.

44 No hay remisión expresa a estas materias, aunque pueda entenderse comprendida en la normación del proceso electoral autonómico, en los Estatutos de Autonomía de: País Vasco, Valencia y Baleares; mientras, el Estatuto de Canarias únicamente se refiere a las inelegibilidades a la hora de remitirse a la ley electoral autonómica. Las referencias normativas se han contrastado en: Estatutos de Autonomía (edición preparada por M.' R. Ripollés Serrano y A. Jiménez Díaz), Senado, Madrid, 1994.

45 (La cursiva pertenece a este trabajo), cfr. el artículo 11.4 in fine del Estatuto castellano leonés. Esta 
En consecuencia, le queda vedado estatutariamente al legislador de esta Comunidad la posibilidad de impedir que estos mandatos locales se acumulen con el regional (salvo previa reforma de la norma institucional).

Dentro del apartado que ahora se comenta debe señalarse que los ordenamientos regionales sobre elecciones no han configurado un sistema homogéneo con respecto a la acumulación de mandatos y, por lo tanto, vamos a tener ocasión de examinar una serie de peculiaridades entre aquéllos. Haciendo uso de las respectivas remisiones estatutarias las normas electorales de las Comunidades Autónomas han regulado la acumulación de mandatos de acuerdo con los siguientes criterios:

$\left.1 .{ }^{\circ}\right)$ Con respecto a los niveles territoriales superiores se reproduce la incompatibilidad con el mandato en el Parlamento Europeo ${ }^{46}$, con el mandato en el Congreso de los Diputados ${ }^{47} \mathrm{y}$, por último - -sólo en algunas Comunidades-, con el mandato de Senador ${ }^{48}$.

2. ${ }^{\circ}$ La relación entre mandatos regionales y locales se ha vertebrado a través de una variedad de orientaciones: por un lado, la ya mencionada compatibilidad contenida en el Estatuto de Autonomía ${ }^{49}$. Por otro lado, la imposibilidad de acumular el cargo de parlamentario autonómico y determinados mandatos locales ${ }^{50}$. En fin, algunas normas electorales, al introducir como actividad incom-

compatibilidad ex estatuto únicamente se prevé también en el caso de Extremadura (art. 23, in fine, del Estatuto extremeño). La mención expresa a la compatibilidad parece traer causa de haber sido inicialmente prevista en los Acuerdos autonómicos de 1981; vid. J. L. CASCAJo CASTro, "Comentario al artículo 11 » en: Comentarios al Estatuto de Autonomía de la Comunidad Autónoma de Castilla y León (dir. E. Rivero Ysern), M. ${ }^{\circ}$ de Administración Territorial e Instituto de Estudios de Administración Local, Madrid, 1985, pág. 109.

46 Así en las leyes electorales de: Aragón (art. 5.2, letra b), Asturias (art. 6.1, letra b), Canarias (art. 4.2, letra b), Cantabria (art. 6.2, letra a), Castilla-La Mancha (art. 6.2, letra b), Castilla y León (art. 5.2, letra a), Extremadura (art. 7.2), Galicia (art. 6.2), Islas Baleares (art. 5.2, letra b) y Murcia (art. 5.3, letra a). Salvo indicación en contra, las referencias normativas a la legislación electoral de las Comunidades Autónomas se han consultado en: E. ARNALdo AlCubiLla y M. DELgado-IribarRen y Garcla-CampeRO, Código Electoral, volumen II, Abella, Madrid, 1995 (2." edic.).

47 Así en las normas electorales de: Aragón (art. 5.2, letra a), Asturias (art. 6.1, letra a), Cantabria (art. 6.2, letra a), Extremadura (art. 7.2), Galicia (art. 6.1). Navarra (art. 5.2, letra a), País Vasco (art. 5.2, letra b), La Rioja (art. 4.2, letra c) y Valencia (art. 6.2, letra a).

48 Esta incompatibilidad existe en las normas de: Castilla-La Mancha (art. 6.2, letra a), Galicia (art. 6.1), Islas baleares (art. 5.2, letra a) y Navarra (art. 5.2, letra b). Como peculiaridad, se introduce como causa de inelegibilidad en Madrid (art. 3.2, letra c). Bien entendido que, cuando se excluye a los Senadores, quedan exceptuados los nombrados en representación de la respectiva Comunidad Autónoma.

49 Recuérdese, en Castilla y León así como en Extremadura.

50 Tal es el caso de la Comunidad gallega, donde se ha introducido como causa de inelegibilidad (art. 4.2, letra b) para los cargos de: Alcalde, Presidente de Diputación y Diputado provincial. 
APROXIMACIÓN AL RÉGIMEN JURIDICO DE LA ACUMULACIÓN ...

patible la dirección o gestión de empresas y sociedades públicas o de participación pública - incluidas las Cajas de Ahorro-, excepcionan de la incompatibilidad a quienes desempeñen las antedichas actividades en virtud de su condición de Presidente de Corporación local ${ }^{51}$.

En lo que atañe al último supuesto, el problema surge en aquellas normas regionales en que, recogiendo la situación de incompatibilidad, no quedan expresamente exceptuados los Presidentes de Corporación local ${ }^{52}$. Habrá, pues, de entenderse que los parlamentarios-presidentes de Corporación local deberán renunciar a las actividades en los consejos de las empresas del sector público señaladas por la norma si desean conservar el mandato regional. Situación comprometida si se tiene en cuenta que su presencia en tales órganos se produce en virtud, precisamente, de la cualidad del mandato local que ostentan $^{53}$.

Resta, para finalizar este apartado, examinar las previsiones normativas específicas para las corporaciones locales. Acaso convenga recordar que las inelegibilidades e incompatibilidades de los miembros de las corporaciones locales resultan de lo que se establezca en la Ley Orgánica Electoral General desde que nuestro Tribunal Constitucional, tempranamente, negara que las elecciones locales fueran régimen particular y no general ${ }^{54}$. Así, en los títulos

51 Asi en: Andalucía (art. 6.2, letra e), Aragón (art. 5.2, letra d), Asturias (art. 6.2, letra d), Canarias (art. 4.2, letra d), Cantabria (art. 6.2, letra b), Galicia (art. 6, letra b, párrafo 2. ${ }^{\circ}$, referido a los miembros del gobierno de las corporaciones locales; pero recuérdese que los Alcaldes son inelegibles), Murcia (art. 5.2, letra c) y La Rioja (art. 4.2, letra b).

52 Esta situación se produce en: Castilla-La Mancha (art. 3.2, letra d), Extremadura (art. 7.3), Baleares (art. 5.2, letra d), Madrid (art. 5.2, letra b) y Valencia (art. 6.2, letra b). No es el caso de nuestra norma electoral que no recoge el mencionado supuesto de incompatibilidad.

53 Esta situación se ha producido en el Congreso de los Diputados, durante la presente legislatura, en los casos de algunos parlamentarios que ostentan a la vez la condición de Concejal o de Alcalde. El problema se suscitaba por la pertenencia de estos Diputados a los consejos de administración de empresas públicas o con participación pública de carácter municipal. Ello colisiona con lo previsto en el artículo 155.2, letra e) LOREG: «Son también incompatibles: (...) e) Los Presidentes de los Consejos de Administración, Consejeros, Administradores, Directores Generales, Gerentes y cargos equivalentes de entes públicos, monopolios estatales y empresas con participación pública mayoritaria, directa o indirecta, cualquiera que sea su forma, y de las Cajas de Ahorro de fundación pública». Precepto que, puesto en conexión con el art. 156.1 del mismo cuerpo normativo, limita la pertenencia a estos entes si el nombramiento o designación corresponde a las Cortes Generales, a cada una de las Cámaras o a las Asambleas legislativas territoriales (no se excepciona, pues, a los entes locales). Entre los casos de incompatibilidad por Jos motivos anteriormente expuestos, destacan: el de la Concejala y diputada P. Rahola (El País, 28 de diciembre de 1996, pág. 17), y los de las Alcaldesas y diputadas C. Villalobos (El País, 13 de febrero de 1997, pág. 27) y T. Martínez (El País, 21 de febrero de 1997, pág. 21).

54 «También es de observar la improcedencia de la pretendida equiparación de las expresiones "régimen electoral general" con "elecciones generales", contraponiendo a su vez estas últimas a las "elecciones locales", 

miembros de los Municipios, Cabildos Insulares canarios y Diputaciones Provinciales ${ }^{55}$.

En lo que atañe a la materia estudiada, las normas electorales únicamente contemplan supuestos de inelegibilidad e incompatibilidad de actividades directamente relacionadas con las funciones que van a desarrollar los miembros de las Corporaciones locales y que pudieran suscitar conflicto de intereses. Es decir, desde la perspectiva local, el legislador de 1985 no ha incluido ninguna previsión de cara a la acumulación de mandatos representativos ${ }^{56}$.

En cualquier caso, el ordenamiento jurídico español solo posibilita un sistema limitado de acumulación de mandatos en tanto en cuanto que se han establecido una serie de filtros: en donde sea posible legalmente, un Concejal puede ser parlamentario regional pero no Diputado en el Congreso, porque hay un impedimento legal entre estas últimas funciones (o bien, si se quiere, el Concejal podría ser a la vez Diputado mas no parlamentario regional). Para la hipotética acumulación con el cargo de Senador, habría que estar al ordenamiento regional, pues alguno, como se examinó en el apartado anterior, sólo la prevé para los denominados «Senadores comunitarios».

para inferir de ello que el texto impugnado en este recurso, al contraerse a la materia citada en último Jugar, nunca puede revestir el carácter de Ley Orgánica por hallarse el mismo reservado al régimen electoral general, según quedó ya reflejado. Y ello en consideración a que el adjetivo "general" no está referido tanto a las elecciones cuanto al régimen electoral», cfr. la Sentencia del Tribunal Constitucional 38/1983, de 16 de mayo, fundamento juridico $2 .^{\circ}$.

55 Véase, concordante, el artículo 73.1 de la Ley de Bases del Régimen Local: «La determinación del número de miembros de las Corporaciones locales, el procedimiento para su elección, la duración de su mandato y la determinación de los supuestos de inelegibilidad e incompatibilidad, se regularán en la legislación electoral» reiterado en el Real Decreto 2568/1986, de 28 de noviembre, por el que se aprueba el Reglamento de Organización, Funcionamiento y Régimen Jurídico de las Entidades Locales (art. 6.1). Vid. P. Garcla MEXIA, «El régimen jurídico de las incompatibilidades de los cargos políticos en el ordenamiento español», La Ley, núm. 4030, año XVII, 7 de mayo de 1996, pág. 2.

56 Otra cosa sucede, sin embargo, con el ordenamiento jurídico francés. Así, el artículo 46.1 del Code Électoral reitera las prescripciones sobre los límites a la acumulación de mandatos creadas por la legislación de 1985, en el caso de los Consejeros municipales; asimismo para los Consejeros generales (art. 206); y también para los Consejeros regionales (art. 342).

Como diferencia con los regímenes jurídicos sobre incompatibilidades en otros niveles territoriales, las normas atinentes a las elecciones locales no señalan el plazo en el que debe ejercerse la opción entre la situación incompatible y el mandato local; vid. sobre este particular L. CosculLuela MONTANER, «Las elecciones locales» en: Tratado de Derecho municipal (dir. S. Muñoz Machado), vol. I, Civitas, Madrid, 1988, pág. 699. 


\section{CONSIDERACIONES EN TORNO A UN HIPOTÉTICO AVANCE EN LA LIMITACIÓN DE LA ACUMULACIÓN VERTICAL DE MANDATOS EN ESPAÑA: ¿HACIA UNA VÍA DE HECHO?}

Como ha tenido ocasión de exponerse, los mandatos susceptibles de ser acumulados (salvo los de parlamentario autonómico y Senador designado por la Comunidad Autónoma) son los de carácter local, bien con los nacionales, bien con los regionales. En relación con estos últimos, se ha visto ya como alguna ley regional ha limitado la presencia de determinados cargos locales en el respectivo Parlamento autonómico. Desde el punto de vista del Congreso y del Senado, nada parece decir expresamente la Ley electoral y, por lo tanto, la regla seguida por ambas Cámaras ha sido la de estimar la compatibilidad del Diputado o Senador que ostenta algún cargo representativo local.

Sin embargo, para algún sector de la doctrina, esta práctica parlamentaria permisiva para con los cargos locales que se sientan en las Cortes Generales debe ser tenida como una «ilicitud de hecho» ${ }^{57}$. Y la ilicitud se hace derivar de la misma norma electoral general, de cuya lectura debiera concluirse necesariamente la incompatibilidad pues, se sostiene, hay base normativa para ello ${ }^{58}$.

Estima el profesor A. FERnÁNDEZ-MiRANDA, en primer lugar, que el enunciado del artículo 157.1 LOREG impide la simultaneidad de funciones desde su extensión a cualquier otro cargo público (en la actualidad a cualquier otro puesto o actividad pública) ${ }^{59}$. Cierto es que las consideraciones del citado constitucionalista se realizaban sobre la redacción anterior, pero nada impediría, tras la modificación operada a través de la Ley Orgánica 8/1991 por la que se reformó la LOREG, seguir manteniendo esta posición si se quiere continuar

\footnotetext{
57 Así A. Fernández-Miranda y Campoamor, op. cit., págs. 272 y ss.
}

58 Como precedente normativo de incompatibilidad expresa puede citarse la Ley de Incompatibilidades de 1933 que, en su artículo $1^{\circ}$, declaraba incompatible con el mandato de Diputado cualquier otro cargo de elección popular; vid. sobre el particular M. MARTINEZ SOSPEDRA, Incompatibilidades parlamentarias en España (1810-1936), Cosmos, Valencia, 1974, págs. 163 y ss.

59 «El mandato de los Diputados y Senadores es también incompatible con el desempeño por sí o mediante sustitución de cualquier otro puesto, cargo o actividad pública, retribuidos mediante sueldo, arancel o cualquier otra forma, salvo los autorizados en la Constitución y en esta Ley Orgánica. Sigue la tesis del profesor FERNANDEZ-MIRANDA, con respecto a la aplicación del artículo 157 LOREG, R. MARTÍNEZ MARTÍNEZ ( «Sobre algunas peculiaridades del status jurídico del parlamentario francés: Delegación del voto y sustitución parlamentaria», Revista de las Cortes Generales, núm. 22, primer cuatrimestre de 1991) al poner en comparación el sistema español y francés (pág. 127 en nota a pie 7). No incluye, por su parte, a los cargos electivos en el tenor de este precepto, R. ENTRENA CuESTA en: "Comentario al artículo 157", Comentarios a la Ley Orgánica del Régimen Electoral General (dir. L. M. Cazorla Prieto), Civitas, Madrid, 1986, págs. 1.290 y ss. 
interpretando ampliamente su tenor ${ }^{60}$. A mayor abundamiento, el autor añade que la Ley electoral de 1985 procedía del malogrado proyecto de 1983 que excepcionaba de la incompatibilidad, de forma explícita ${ }^{61}$, a los cargos electivos de representación popular excepción que, sin embargo, no ha sido contemplada, finalmente, por la norma de $1985^{62}$.

Sostiene, en segundo lugar, que el adjetivo «retribuido» con que se califica a los cargos incompatibles no es enervable operando a través del régimen previsto para la «incompatibilidad retributiva», esto es, que puedan simultanearse funciones pero únicamente pueda cobrarse una retribución pública ${ }^{63}$. La razón deriva de que la propia naturaleza de los cargos declarados incompatibles es, según el precepto, que son retribuidos, es decir, la ley incompatibiliza la función, no la retribución y, por ende, aun renunciando a ella no cabe la compatibilidad $^{64}$.

Por fin, se acude todavía, en tercer lugar, a una razón más poderosa. En nuestro sistema, todas las causas de inelegibilidad lo son de incompatibilidad (art. 155.1 LOREG) y, en virtud del artículo 6.3, letra b) LOREG, son inelegibles los «Presidentes, Directores y cargos asimilados de entidades autónomas de competencia territorial limitada, así como los Delegados del Gobierno en las mismas». Con este precepto, se estima, no cabría ni siquiera la concurrencia de los cargos representativos locales -en este caso, específicamente, los Al-

60 Según el actual art. 157.2: «En virtud de lo establecido en el apartado anterior, el mandato de los Diputados y Senadores será incompatible con el desempeño, por sí o mediante sustitución, de cualquier otro puesto, profesión o actividad, públicos o privados, por cuenta propia o ajena, retribuidos mediante sueldo, salario, arancel, honorarios o cualquier otra forma (...)».

61 El artículo 2.3 del Proyecto de Ley Orgánica sobre Incompatibilidades de Diputados y Senadores disponía que: «La condición de Diputado o Senador es compatible con el desempeño de cargos electivos de representación popular, con la salvedad establecida en el apartado I de este artículon. El texto se ha consultado en: M. Fralle Clivilués, Código Constitucional, tomo II, Trivium, Madrid, 1984, págs. 813 y 814 .

62 El Proyecto de Ley Orgánica de Incompatibilidades de Diputados y Senadores, de 1983, fue declarado inconstitucional por el Máximo intérprete de la Constitución al entender que, a pesar de su carácter orgánico, no reunía las características para ser estimado como ley electoral y, por lo tanto, cumplir los requisitos de remisión del artículo 70.1 de la Constitución ( $c f r$. la Sentencia 72/1984, de 14 de junio). Por su parte. E. Jiménez APARICIo (Régimen jurídico de las retribuciones de los Diputados y Senadores, Centro de Estudios Constitucionales, Madrid, 1994), hace derivar la incompatibilidad de la no previsión expresa de compatibilidad (cfr. pág. 547, en nota a pie núm. 132).

63 Cfr. los artículos 157.2, párrafo $2^{\circ}, 157.4$ y 158.1 LOREG.

64 Aunque la incompatibilidad que predica el profesor A. FERNÁNDEZ-MIRANDA recae sobre Alcaldes y Presidentes de Diputación nada impediría, según su tesis, que se aplicara también a los Concejales en cuanto éstos, en función de la legislación local, pudieran cobrar retribución. En este sentido, vid. E. JıMÉNEZ APARICIO, quien se muestra rotundo sobre la imposibilidad de enervar la incompatibilidad retributiva a través de la renuncia a una de las percepciones económicas (cfr. idem). 
APROXIMACIÓN AL RÉGIMEN JURIDICO DE LA ACUMULACIÓN ...

caldes y Presidentes de Diputación - a las elecciones generales (sin renunciar previamente al mandato inferior), ni compatibilidad si el Diputado o Senador fuera elegido Concejal, Alcalde o Presidente de Diputación a posteriori.

Otra es, no obstante, la posición defendida en este trabajo. Cierto es que quienes ostentan mandatos locales son «cargos públicos» $\mathrm{y}$, además, representativos ${ }^{65}$. Mas cuando la Constitución, o la ley electoral, restringen la acumulación de mandatos, lo hacen explícitamente y no a través de una cláusula general proyectada sobre cualquier cargo público y, si bien es verdad que se suprimió la excepción contenida en el fenecido proyecto de 1983, no es menos cierto que, precisamente, no hay ninguna referencia explícita a la incompatibilidad de los mandatos locales en las normas ad hoc. Téngase en cuenta, por otro lado, que es doctrina reiterada por nuestro Tribunal Constitucional que, desde la relación de las inelegibilidades e incompatibilidades con el derecho fundamental de acceso a los cargos públicos (art. $23.2 \mathrm{CE}$ ), la aplicación de ambos institutos jurídicos debe interpretarse restrictivamente por el operador jurídico que huirá del criterio analógico a la hora de su determinación ${ }^{66}$.

¿Estamos verdaderamente ante una incompatibilidad funcional y no meramente retributiva? Pudiera parecer que, efectivamente, de acuerdo con el artículo 75.1 de la Ley de Bases del Régimen Local, los cargos locales en determinados supuestos tienen la consideración de «retribuidos» de forma imperativa ${ }^{67}$. Sin embargo, no parece posible sostener la ineludible naturaleza retributiva de aquéllos cuando el artículo 13.4, del antes citado Reglamento de organización municipal, faculta la no aceptación, por parte de interesado, de la dedicación exclusiva declarada previamente por el Pleno de la corporación local (y por ello de la consiguiente percepción pública con cargo a los presupuestos municipales).

En fin, con relación al último argumento, éste parece descansar en que los municipios y provincias son «entidades autónomas de competencia territorial

65 Ya sean de primer grado si proceden directamente de las urnas (Concejales), ya sean de segundo grado si son elegidos por los de primer grado (Alcaldes, con las excepciones de elección directa marcadas por la ley, y Presidentes de Diputación).

66 Así entre otras las Sentencias 45/1983, de 25 de mayo y 28/1986, de 20 de febrero. Disiento, pues, de E. Jiménez APARICIO en el sentido de que es la incompatibilidad y no al envés - la compatibilidadla que debe figurar, en el supuesto de los cargos representativos, de forma expresa en la correspondiente norma jurídica.

67 «Los miembros de las Corporaciones locales percibirán retribuciones por el ejercicio de sus cargos cuando los desempeñen con dedicación exclusiva (...)").

Existe, no obstante, doctrina reacia a otorgar naturaleza retributiva a los cargos representativos locales; así, por ejemplo: L. MORELl OCAÑA, El régimen local español, tomo I, Civitas, Madrid, 1988, pág. 500 para los Concejales y 56 para los Alcaldes, respectivamente. 
limitada», acaso, en conexión con el artículo 137 de nuestra Constitución ${ }^{68}$. Sin embargo, el texto del artículo 6.3, letra b) LOREG, ha de interpretarse en su contexto. Así, anteriormente, el artículo 6.1, letra m) del mismo cuerpo normativo, establece la inelegibilidad absoluta (es decir, no cabe la presentación de la candidatura en ninguna circunscripción del territorio nacional) de los «Presidentes, Directores y cargos asimilados de las entidades estatales autónomas con competencia en todo el territorio nacional». Por ello, la inelegibilidad relativa (aquella que sólo opera en la circunscripción donde se desempeñen las funciones), prevista en el citado artículo 6.3, letra b), parece referirse no tanto a los cargos de los órganos de los entes derivados del artículo $137 \mathrm{CE}$, sino a los cargos directivos de los órganos periféricos de la Administración institucional ${ }^{69}$ Cargos públicos, sí, pero de naturaleza administrativa, mas no representativa.

¿Podría subsumirse en esta causa de inelegibilidad a los Presidentes de corporaciones locales cuando, en función de su cargo, presidan entes autónomos locales? Éstos, ciertamente, van a desplegar su eficacia en un territorio limitado, pero ello no puede ser de otra manera si sirven a los intereses de los órganos locales. La esencia de la Administración institucional no es territorial, pues incluso la local o regional actúa sus competencias en todo el territorio regional, provincial o municipal y, la inelegibilidad del art. 6.1, letra m) LOREG, al afectar a los cargos de Administración institucional con competencia en todo el territorio, se refiere a aquella de naturaleza «estatal».

Ello no quiere decir que el legislador, lege ferenda, no pueda plantearse la interdicción total de la acumulación de mandatos dando el paso definitivo hacia los locales. No nos corresponde a nosotros enjuiciar opciones políticas. Pero, si bien es cierto que el Derecho ampara la existencia de distintas opciones, también lo es que impone los procedimientos para llevarlas a cabo. La posición que aquí se defiende es que solamente es posible prohibir la acumulación de mandatos, de forma expresa y ex lege. Para ello se pueden utilizar dos mecanismos jurídicos de larga tradición: bien estimando que los cargos locales influyen en la libertad del elector a la hora de formar su voluntad y que colocan a los candidatos en situación de desigualdad y, entonces, los debería declarar inelegibles para las Cortes Generales (y por ende, en virtud del artículo 155 LOREG, incompatibles). Bien, estimando que los mandatos locales únicamente socavan la independencia del mandato parlamentario entrando en conflicto

\footnotetext{
68 «El Estado se organiza territorialmente en municipios, en provincias y en las Comunidades Autónomas que se constituyan. Todas estas entidades gozan de autonomía para la gestión de los respectivos intereses.» (La cursiva pertenece a este trabajo).

$69 C f r$ en este sentido algunas resoluciones de la Junta Electoral Central: Acuerdos de 5 de mayo de 1977 «Directores Provinciales de Organismos Autónomos» y de 3 de abril y 5 de mayo de 1987 «Directores de Juntas de Obras del Puerton; vid. el citado Código Electoral, en su volumen I.
} 
APROXIMACIÓN AL RÉGIMEN JURTDICO DÉ LA ACUMULACIÓN ...

con éste y, por ello, arbitrar ex novo una causa de incompatibilidad que no impide la concurrencia a las elecciones pero sí obliga, una vez se ha resultado válidamente electo, a optar entre los mandatos incompatibles.

Mientras tanto, ante una eventual declaración de incompatibilidad por los órganos parlamentarios competentes, sustentada según nuestro entender en una interpretación tan extensiva y forzada de la norma, cabría la interposición de un recurso de amparo ante el Tribunal Constitucional ex artículo 42 LOTC por vulneración del derecho fundamental contenido en el artículo 23.2 CE. 
